\title{
THE DYSLEXIC STUDENT'S EXPERIENCE OF EDUCATION
}

\section{S. Thompson}

School: Humanities and Social Sciences

The IIE's Varsity College

Cape Town, South Africa

https://orcid.org/0000-0002-4472-0048

\section{ABSTRACT}

This article explores the lived experiences of students with dyslexia at public universities. The researcher conducted a qualitative phenomenological study using Interpretative Phenomenological Analysis and collected data via semi-structured, in-depth interviews from university students who have all been formally diagnosed with dyslexia. Three main themes emerged from the data: (1) barriers to learning (2) coping strategies employed by dyslexic students, and, (3) the support offered by university structures. The findings indicated that dyslexic students experience a significant amount of anxiety at university, and this is often linked to the lack of societal awareness of dyslexia by academic staff. The findings also revealed that although dyslexic students face barriers to learning that they must overcome, they are equipped with selftaught coping mechanisms. The main conclusion that can be drawn from this study is that if dyslexic students receive the necessary and appropriate support, they can be as successful as their non-dyslexic peers.

Keywords: dyslexia, barriers to learning, disability, higher education, inclusion

\section{INTRODUCTION}

Dyslexia is a specific learning disability that impacts one's ability to gain the necessary skills for effective reading (International Dyslexia Association 2008). It is a lifelong disability, and the difficulties that individuals experience at school continue into higher education (Heiman and Precel 2003). The ability to read and write properly pose even more challenges to the dyslexic individual as the expectation for effective note taking and academic writing is higher at tertiary level (Lopez-Escribano, Sanchez and Carretero 2018). Globally, there is indication that higher education institutions are seeing an increasing student population with disabilities (particularly dyslexia) (MacCullagh 2014). Even though official statistics for South Africa are not available, a project undertaken by Foundation of Tertiary Institutions of Northern Metropolis (2011), revealed that disabled students constitute only 1 per cent of higher education enrolments in South Africa. However, research shows that more students with dyslexia are entering tertiary institutions than previously. Unfortunately, research also shows that while participation and enrolment rates have increased, drop-out rates are high and graduation rates 
are low for postsecondary students with disabilities, and in particular those with learning disabilities (Denhart 2008; Lightfoot, Janemi, and Rudman 2018). The high drop-out rate could be attributed to a universal lack of understanding, awareness and support of disabilities in the higher education context (MacCullagh 2014). Due to the increased enrolment figures globally, it is imperative that universities accommodate the academic needs of students with dyslexia. Doering (2003) states that universities have an ethical duty to provide reasonable support for their students throughout their course of study. According to Pirttimaa, Takala, and Ladonlahti (2015), awareness of dyslexia in higher education has increased but a deep understanding of this disorder is still lacking, and university staff remain largely ignorant about the complexities of this learning disability. The rationale for this research article stemmed from the need to understand the experiences of dyslexic students in higher education in order to provide the necessary stakeholders with guidelines for appropriate support interventions.

This study describes the experiences of dyslexic students at university. It provides insight into the impact of attitudinal, environmental, and policy barriers that dyslexic students face. It also investigates the coping mechanisms that these students employ to overcome barriers and whether their academic needs are being met at public universities. The findings of the study are used to provide practical guidelines to universities that can improve the experiences and academic success of the dyslexic student.

\section{LITERATURE REVIEW}

Many public universities in South Africa offer students with dyslexia particular concessions for assessment purposes and may feel that this covers the realm of inclusion. It should be emphasised that even though institutions claim their policies are inclusive, they cannot assume they are meeting the needs of the student. According to Morrison, Brand, and Cilliers (2009), institutions must be proactive in their approach to achieving greater inclusivity. Institutions must address barriers such as teaching methods, assessment options, and the attitudes of staff and other students (Morrison et al. 2009). The Council on Higher Education reported in 2005 that higher education institutions in South Africa were not adequately supporting students with disabilities.

Dyslexic students constitute the biggest group of students with disabilities at tertiary level (Pino and Mortari 2014). Despite the rising number of dyslexic students enrolling at public higher education institutions in South Africa (FOTIM 2011), these students have not been given the opportunity to describe their experiences. It is imperative that their voices be heard so that institutions can be informed of the possible attitudinal, environmental, and policy barriers they may face (Vickerman and Blundell 2010). Once institutions are informed of these barriers they 
can ensure that these can be overcome or reduced to ensure dyslexic students have the best possible chance for academic success.

It is essential to understand the lived experiences of students with dyslexia in order to get a "true" sense of the challenges and obstacles they face, the barriers that may hinder academic success, and the coping strategies they employ to achieve success (Mullins and Preyde 2013).

\section{Disability and dyslexia}

Dyslexia is a life-long learning disability that results in individuals struggling with reading, spelling, writing, mathematical calculations, and/or speaking. In addition to these primary characteristics, dyslexic individuals also experience secondary characteristics, such as high levels of stress and anxiety, which can be associated with repeated academic failure or the exposure of not being able to spell in public settings (MacDonald 2010). Individuals with dyslexia experience these characteristics to varying degrees and despite adequate instruction and average to above-average intelligence. It is suspected that somewhere between 10 per cent and 20 per cent of the global population experiences some degree of dyslexia. Although the exact cause of dyslexia remains unclear, research shows that it occurs in people from all backgrounds and tends to run in families (IDA 2008). It is usually detected and diagnosed (if at all) at primary school when the child first learns to read. Although it is a lifelong disability, dyslexic individuals can learn to read and write well, often devise coping mechanisms to compensate for their weaknesses, and frequently go on to become very successful in their chosen careers.

The framework used to conduct this study is the social model of disability. The basic premise of this model is that people are not disabled because of their deficiency but rather because of society's negative attitudes, ignorance, and/or discrimination towards disability (Toutain 2019). According to Riddick (2001), society places a huge emphasis on the ability to read, write, and spell. Society's negative attitudes towards people who are believed to be unable to engage adequately in these cognitive tasks is what advocates of the social model of disability deem to be disabling. Reading and writing are not adaptive skills. Centuries ago people did not have a written language and were therefore not considered disabled. Written language is therefore a "modern" social construct, and the social model argues that individuals are considered disabled when they are unable to perform these functions to society's norms and standards (MacDonald 2009). Therefore, dyslexics should not be classified as disabled as it is the environment that has rendered them disabled and not their impairment. From this perspective, dyslexia is unfairly and unjustly seen as a disability. 


\section{Dyslexia and higher education}

Previous research has shown that dyslexic students feel that universities do not offer them enough appropriate support (Carroll and Iles 2006). Students want support that is flexible if, and when, they need it. While some praised the support units at universities, many reported that fellow students offer more of a support base than the actual university structures (Mortimore and Crozier 2006). Students perceived academic staff to be either disinterested or unable to assist them. Students also expressed disappointment that universities do not offer alternatives to traditional assessment methods (Cameron and Nunkoosing 2012).

Despite the demands placed on dyslexic students, research shows that they still manage to achieve academic success. They find ways of coping and adapting to the demands placed on them by the higher education environment, and they tend to have better than average coping skills (Carroll and Iles 2006). Coping skills could be a greater contributor to their academic success than the minimal support provided by institutions. Although many barriers exist within the higher education arena, dyslexic students often showed remarkable resilience and hardiness in coping with their disability (Carroll and Iles 2006).

Research shows that there is a need to increase awareness levels about the nature of dyslexia and its implications for students among university academics. Nolan et al. (2014) stated that many universities globally have made huge strides to accommodate students with disabilities, including those with "hidden disabilities", although it is still unclear whether this is due to the increased efforts of the disability rights movement or due to more students declaring their disability. However, this increase in student numbers can be largely attributed to the social model perspective, which ensures the integration of disabled individuals in society as a whole. Along with these increases at many universities internationally, the provision of appropriate support has been highlighted (Nolan et al. 2014). The issue of student support is crucial to the success of students with disabilities in higher education. Lyner-Cleophas et al. (2014) reported that the most problematic areas experienced by disabled students are teaching and curriculum practices. Students have stated that it is not enough to just provide extra time in assessments or examinations, but that lecturers and other staff need to be mindful of the specific constraints of students' disabilities. It is argued that most students (especially those with "hidden disabilities") do not declare their status and therefore cannot receive the necessary support. The disclosure of one's disability status is paramount to receiving appropriate support. The teaching and curriculum practices reported by Lyner-Cleophas et al. (2014) constitute environmental and attitudinal barriers to inclusion. Ryan and Struhs (2004) commented that attitudinal and environmental barriers exist within Australian universities, and that these barriers impede full participation of disabled students in university life. According to a report 
by Vickerman and Blundell (2010), there are two other important categories of barriers that impact on full inclusion, namely attitudinal barriers and policy barriers.

As previously stated, the social model perspective (SMP) argues that it is the barrier that renders individual disabled, not the impairment itself. Research shows that in order to truly accommodate students with disabilities at an institutional level, the institution must consult disabled students directly regarding their specific needs (Vickerman and Blundell 2010). According to the SMP, the experiences of disabled students must be heard. The model warns against providing "support" for students without consulting them and therefore potentially providing support that is either inadequate or inappropriate.

After signing the Salamanca Agreement in 1994, South Africa heeded the call to ensure inclusive education not only in schools but also in public higher education institutions (LynerCleophas et al. 2014). However, despite the fact that the South African government has committed itself to providing inclusive higher education, unlike in some developed countries (e.g., the USA and the UK), there is no legal obligation to do so (Matshedisho 2010).

Mullins and Pryde (2013) claim that barriers to learning disempower and marginalise dyslexic students. According to the literature, access to the physical environment, followed by accommodations and concessions, are paramount in creating a truly inclusive system of education. Public universities have policies to ensure access, but disabled students still reported that they experience huge barriers to learning (Ntombela 2013). Removing and/or reducing barriers to learning play a huge role in promoting academic success and overall positive student experiences. Three types of barriers that negatively affect dyslexic students include: environmental, attitudinal and policy barriers.

Environmental barriers include a lack of support staff and/or resources, ineffective or lack of alternative teaching methods, and a text-heavy information society. Attitudinal barriers include negative staff attitudes or poorly trained staff, although both academic and support staff often report a sense of helplessness at not being able to effectively support and accommodate students with disabilities (Nolan et al. 2014). Policy barriers include the lack of clear and definitive governmental or institutional policies to facilitate inclusion. Students have reported that the kinds of environmental barriers they face include inappropriate teaching and assessment methods, lack of reasonable infrastructure, and large amounts of content to be examined (although students with no disability may also consider this as a barrier) (Doikou-Avlidou 2015). Doikou-Avlidou's (2015) study revealed that dyslexic students feel that the removal of these barriers would go a long way in assisting them to achieve academic success. Supporting results from a previous study disclose that inappropriate and exclusive teaching methods and inflexible curricula are huge obstacles to learning (FOTIM 2011). Best practice involves the 
design of curricula and assessments with all students in mind. This principle is based on the social model theory, which posits that it is the environment that must fit the disabled individual (and student), not the disabled individual who must fit into the environment. This principle addresses environmental barriers while still acknowledging the limitations disabled individuals face because of their impairment. Designing buildings that are accessible to everyone and inclusive lecturing styles that accommodate most impairments (FOTIM 2011) would go a long way in reducing some of the limitations experienced as an environmental barrier. Researchers agree that barriers such as limited or inflexible curricula, the design of the built environment, teaching methodologies, and assessment practices are inherent barriers to dyslexic students in South African higher education (Matshedisho 2010).

The social model allows a framework of investigation and documentation of the experiences of dyslexic students in higher education. While Shevlin, Kenny, and Mcneela (2004) argued that the experiences of dyslexic students in higher education have not been fully explored and need further investigation, common themes have emerged from the current literature. Key themes that have been reported in the literature include the barriers dyslexic students face and have to overcome, the coping mechanisms they often have to employ to achieve academic success; and the support provided within universities for students with disabilities (Denhart 2008; Mutanga 2018). These themes were explored in this study.

According to a study conducted by Shevlin et al. (2004), students with disabilities in higher education report negative attitudes as the most significant barrier to their progress. Those responsible for informing policy and implementing practices may possess negative attitudes which are covert barriers, (inherent in institutions). Negative individual attitudes many also be displayed by academic, support, and administrative staff (FOTIM 2011). One of the main types of attitudinal barriers reported by students was that of negative lecturer attitudes, which included ignorance about disability (and dyslexia) as well as being unwilling or unable to (a) acknowledge disability (especially "hidden" disability such as dyslexia), (b) provide support such as flexible curricula, (c) adapt teaching methods, and (d) modify assessment tools and techniques (Matshedisho 2010; Toutain 2019). These negative attitudes often mean that students are reluctant to seek out support (or even disclose their disability) due to potential stigmatisation. Lecturers who are knowledgeable about dyslexia were both in a better position and seemingly more willing to support their students, which contributed to students' academic progress (Doikou-Avlidou 2015).

Despite the many policies, environmental, and attitudinal barriers that exist in higher education, students with dyslexia continued to thrive and succeed academically. The following fundamental question could therefore be posed: how do dyslexic students succeed in the midst 
of the many barriers they face? According to Pirttimaa et al. (2015) one of the most significant coping mechanisms involved compensatory strategies. It is evident in literature that dyslexic students compensated for their difficulties and often used self-taught (individualistic) strategies in order to navigate their studies. These strategies were usually adopted while in high school and then either improved upon or modified to suit the higher education environment (DoikouAvlidou 2015). The primary difficulties associated with dyslexia became more apparent in higher education due to the additional academic demands placed on the student, which exacerbated their challenges. According to Doikou-Avlidou (2015), many students reported that their compensatory strategies improved after high school, and they attributed their academic success to their "new and improved" skills acquired at university. Dyslexic students often utilised strategies that are "tailor-made" to their individual needs and these differed from one student to another. Not only did students report that their self-taught strategies resulted in academic success, but they also improved their sense of power and sense of self-worth (Pirttimaa et al. 2015).

Pirttimaa et al.'s (2015) study also revealed that because the dyslexic student is already academically vulnerable, appropriate and reasonable support is therefore paramount to this group of students. Many studies reflect that disability support within universities were provided in different forms (and to differing degrees) and often based on levels of resources and funding available to the institution (Taylor et al. 2016). The types of support offered by universities included extra time in assessments, scribes, not takers, assistive technology/software, tutorial classes to name a few (Beckett and Darnell 2020).

Based on the literature presented, this research study examined the barriers dyslexic students faced, the coping mechanisms and compensatory strategies they employed in order to succeed in South African higher education (public universities) settings, and the support offered by the university structures and the disability unit in particular. This was achieved by giving credence to dyslexic students' voices. The FOTIM (2011) report articulated it well by stating that the benefit of giving voice to the personal experiences of students with disabilities allows individuals express their lived experience of higher education.

\section{METHODOLOGY}

\section{Recruitment}

The sample was purposively chosen from the study population, namely dyslexic students at public universities in South Africa. The sample included undergraduate and postgraduate dyslexic students registered at, or recently graduated from, universities in the Western Cape. 
The final sample comprised of 11 formally diagnosed dyslexic students from four public universities in the greater Cape Town region. All participants were formally diagnosed with dyslexia at either primary school or high school. This size sample was deemed sufficient in qualitative research as it involves exploring participants' knowledge, perceptions, and experiences of the phenomenon under study. This sample size was also sufficient for this study, as the data saturation point had been reached. Three modes of participant recruitment were used, namely Facebook, and flyers on campus noticeboards and university structures advertising the study on behalf of the researcher.

\section{Materials}

A researcher-designed, semi-structured interview comprised of a series of open-ended questions was used to generate rich, detailed responses from participants. The interview questions were based on the literature and objectives of the study and were linked to the key themes investigated in the study.

The guide comprised of two sections: a demographic survey and the interview questions. A pilot study was conducted with one participant to pre-test both the interview guide and questions, as well as the data collection process. No amendments were made to any part of the interview guide upon the conclusion of the pilot study.

\section{Interviews}

All participants were interviewed individually using the semi-structured, in-depth interview. Interviews were conducted at a place and time suitable to both participant and researcher. Participants' responses were audio recorded so that they could be transcribed at a later stage. This allowed the researcher to focus on, and document, the participants' non-verbal language in addition to what they are saying during the interview process. Interviews lasted between 45 minutes and one hour depending on the amount of detail each participant provided. No incentives were offered to participants before or after the interviews were conducted.

The data were stored electronically on the researcher's personal computer. Once interviews were conducted, the transcriber transcribed the data verbatim from audio to text. When this process was completed, the data were analysed.

Ethical clearance and permission were sought from relevant gatekeepers, and informed consent was obtained from all participants. There were no physical or psychological risks to the participants. 


\section{Data analysis}

An interpretative phenomenological approach (IPA) was utilised to analyse the data. Interpretative phenomenology is used to seek meaning behind the phenomenon being explored. Thus, the researcher strives to explore and interpret the meaning participants ascribe to their lived experiences without bracketing their biases and prior engagement with the phenomena under study.

\section{FINDINGS}

The findings of this study are structured around the master themes that emerged from the data, namely: (1) barriers to learning (2) coping strategies employed by dyslexic students at university, and (3) support offered by university structures. These themes are supported by verbatim quotations from participants' interviews.

\section{Barriers to learning: Attitudinal, environmental, and policy barriers}

Participants reported that there are many barriers (attitudinal, environmental, and policy) that impede on their academic success at university. The main barriers include (a) stigma, (b) negative lecturer attitudes, (c) lack of awareness about dyslexia, and (d) lack of specific policies for the provision of service and support for dyslexic students. The following excerpts reflect this situation:

"... the assumption that I am stupid was more a stigma than dyslexia ...."

"I think a lot of it was like oh you just naughty or lazy ..., why are you so being lazy, why, why are you resisting doing your work, you have a brain, why aren't you using it ...."

"I do have some lecturers who don't put their slides up; (but) in one of my lectures, they refused to ...."

"Yes. So, I have a literal fear of emailing my lecturers to ask them any questions because I know, I just ... so, I will spend the extra time bugging them after lectures ...."

"And I seeing, so like, with that I am like, well you know, I organise my own scribe, I am paying for my own scribes ...."

“... my friend says I am really struggling to read 'The prologue to the Canterbury Tales' and I am like ... you don't understand what it's like to struggle reading normal English ... I mean they are not being insensitive, like, of course they are not ...."

“... the tutor will be like, so has everyone read the book; and ... people will be like, yes I have read half of it; and he will like, XXX how much have you read; and I would say like, I have nearly finished the first chapter; and I think people kind of thought I was joking ...."

"I had to learn to deal with it; where I come from people are very closed minded ... So, at the young age I just learnt, they need to get over it."

"because it's not just enough to do orientation (advertising of support services), because maybe you need that support in 2nd year or 3rd year or honours, and so, must be repeated." 
The main finding related to the potential and perceived attitudinal, environmental, and policy barriers dyslexic students face at university is the ignorance and lack of awareness of dyslexia that continues to prevail at public universities.

\section{Coping strategies employed by dyslexic students at university}

Dyslexic students at public universities employ various strategies to cope with their learning disability to achieve academic success. Individual learning techniques, disclosure of one's dyslexic status, understanding one's strengths and limitations, and work ethic are among some of the coping strategies dyslexic students use to achieve academic success. The quotations below reveal some of the coping strategies employed by participants:

"I went straight to the Disability Unit and had a meeting with the co-ordinator, because I knew the workload is going to be more ... and I knew, like, this is going to be a struggle ...."

"I think it is harder because you have to work harder than anyone else ...; disclosure is needed because if you don't disclose people will make false assumptions about you ...."

"I would rather just use the facilities available to me."

"... the thing is, it's just better for you ...."

"Then I realised I needed help."

"Some of these coping strategies I have done for so long now I can even notice them doing ...."

"I learnt so many tricks and so many techniques by the time I was in university ... I was on the Dean's list every year."

"I summarise my textbook work; and that used to be in multiple colours each section ... it varied by subject ... and then ... I managed to get through all that and I make notes, I note everything because I struggle to remember details ...."

"I put in a lot of effort, it was quite a big adjustment ... going to spaces where you know no one really caters for your disability ... you are just a student and if you have a problem, you actually have to go and find the solution."

"Then I would watch the YouTube videos and figure it out from there because then at least if there's something I didn't understand I could just pause and rewind ... and make notes or kinda figure it out for myself through - that helped a massive amount."

The findings in this study suggest that coping strategies are strong contributing factors to the academic success of dyslexic students. Issues such as specific learning techniques, disclosure of learning disability status, work ethic, and individual strengths all emerged as coping strategies responsible for the academic success of dyslexic students. 


\section{Support offered by university structures}

The data revealed that the main sources of support for dyslexic students at public universities are the resources and services offered by campus disability units.

"I think for a start, making the Disability Unit more present on the campus will be a massive help." "In undergrad, the things that come to mind initially are the Disability Unit is really good; they really, really helped me, because I needed a scribe ... and they organised that; you send an email and like in a week or 2 before your test and they would sort it all out for you; which meant you didn't have to organise [your scribe] yourself; and also you didn't have to interrupt the lecturers."

"The DU is very supportive. Because XXX (head of disability unit) also has a disability ... And because she is also disabled, she doesn't allow you to feel sorry for yourself. She would say to me you must fend for yourself because the world is not going to do that for you."

"... but if you disclose, people actually tend to accommodate you."

"So, I mean there are things like the extra time, I think like the scribes, I think like using the computer, all of those things sort of limit how well that person can do in that space, with the help, maybe not so well, maybe without the help ...."

The most important finding in this theme is the level of support provided by the disability units at all the universities represented in the study. The findings in this study reveal that the main type of support required by dyslexic students at university is the provision of concessions and accommodations for assessments and examinations.

\section{DISCUSSION}

\section{Barriers to learning: Attitudinal, environmental, and policy barriers}

The main finding related to the attitudinal, environmental, and policy barriers dyslexic students face at university is the lack of awareness and societal ignorance around dyslexia that continues to prevail at public universities. This finding is consistent with MacCullagh's (2014) previous research that stated that a lack of awareness and support for dyslexia is universal. A significant finding of this study is the fact that participants feel that dyslexia is still stigmatised, and that society is unaware of the negative impact this has on the individual. This finding is supported by Shevlin et al. (2004) who found that disabled students believe that negative attitudes towards disability are the most significant obstacle to academic progress. Unfortunately, participants in this study also reported that university staff displayed negative attitudes and a lack of awareness of dyslexia. This finding corroborates that of Mullins and Preyde (2013) who found that the negative attitudes of lecturers is a major barrier faced by students with varying learning styles and often leaves students feeling ostracised. This research study extended Cameron and 
Nunkoosing's (2012) finding that academic staff were either disinterested or unable to assist students as some participants recalled instances where lecturers or tutors showed a lack of awareness or empathy about their struggles with dyslexia. Perceived negative lecturer attitudes is also cited as one of the reasons for students' lack of disclosure in this study. Such attitudes are not conducive to the academic progress of dyslexic students and more needs to be done to heighten lecturer awareness of dyslexia.

This study also extended the findings of Lyner-Cleophas et al. (2014) that reported that one of the most problematic areas experienced by disabled students are teaching and curriculum practices. This was, to some degree, reflected in this study as participants reported that some of their lecturers were unwilling to provide them with lecture slides which is seen as an assistive teaching practice. It is also clear that based on stigma reported in this study, that increased awareness levels about the nature of dyslexia and its implications for students among university academics is paramount as reported by Nolan et al. (2014).

According to Lapraik (2012), universities must also be aware of their organisational culture and whether it strives to build an inclusive environment. As reflected by participants in this study, this could be achieved in many ways, with ongoing advertising of support services for students at all levels of study as an example. It is the university's obligation to adapt their environment and not the responsibility of the dyslexic individual to change to fit into the culture of the university. Participants in this study also commented that dyslexic students may be unwilling to seek assistance if the logistics of receiving accommodations is too cumbersome. If this is the case, then the university environment is not adaptive to, and inclusive of, the students' needs.

A report by (FOTIM 2011) claimed that inappropriate and exclusive teaching methods and inflexible curricula are huge obstacles to learning. Participants in this study, however, did not report specifically and directly on teaching and learning strategy or curriculum design and its impact on their success. However, the researcher believes that this may be due to the fact that they are potentially unaware of its impact on learning. Some participants did, however, comment on extremely large classes at public universities and the negative impact this has on the lecturer's inability to address the individual needs of dyslexic students in such large classes. In order to be truly inclusive, universities should design their teaching and learning strategy and institutional policies and structures to accommodate all students, and the provision of concessions and accommodations should not be made on an ad hoc basis. As such, the term environment is an all-encompassing one that includes student support at all levels.

While most participants did not report any policy barriers per se, it was found that these may exist in a way that is not apparent to students. The biggest policy barrier at all of the 
universities attended by participants in this study is support services provision that continue to be framed within the medical model of disability. This contradicts the social model of disability framework that highlights the fact that a disability does not "lie within" the individual. Dyslexic students are still required to provide a formal evaluation and diagnosis (based on the medical model) of their learning disability from a clinical practitioner, even when this service is offered by the university. Lapraik (2012) stated that while higher education institution policies theoretically support the social model of disability, in practice the medical model continues to prevail. Requesting that students submit evaluation and diagnostic documentation is in opposition to the tenets of the social model of disability. However, it can be appreciated that this documentation may be required as universities may have no other way of ensuring that students who are genuinely deserving of the concession and accommodations receive them.

Another primary barrier is the lack of clear national policy guidelines specifically for support services for dyslexic students at university. Such guidelines would ensure that dyslexic students receive the same support services, irrespective of the university they attend, without having to depend on the benevolence of university staff and the funding available to their respective university.

\section{Coping strategies employed by dyslexic students at university}

The findings in this study suggest that coping strategies are strong contributing factors to the academic success of dyslexic students. Issues such as specific learning techniques employed by dyslexic students, disclosure of learning disability status, work ethic, and individual strengths all emerged as coping strategies responsible for participants' academic success. Almost all the coping strategies identified in this study are self-taught and developed, and all participants reported that they rely on their coping strategies to achieve success. There are similarities between the experiences expressed by participants in this study and those described by Pirttimaa et al. (2015), who reported that dyslexic students possess many self-taught strategies that compensate for their difficulties and allow them to navigate their studies. However, a study by Henderson (2017) revealed that the coping strategies employed by dyslexic students only assist them in their first year of university as these strategies are not adequate to manage the increased academic load in the second and third year of undergraduate studies. Thus, the findings in this research study do not support Henderson's (2017) findings.

\section{Support offered by university structures}

The most important finding related to the experience of dyslexic students is the level of support provided by university structures. The findings in this study reveal that the main type of support 
required by dyslexic students at university is the provision of concessions and accommodations for assessments and examinations, which corroborates Pirttimaa et al. (2015) findings that suitable and reasonable support is vital to the academic success of dyslexic students. Beckett and Darnell (2020) further reveal that the types of support offered by universities included extra time in assessments, scribes, not takers, assistive technology/software and tutorial classes. Participants in this study confirmed that they required concessions and accommodations such as extra time in assessments, scribes and assistive technology/software.

As reported by Maggiolini and Molteni (2013), academic success is considerably affected by the commitment of university staff to provide accommodations to students. It is pleasing to note in this study that support to dyslexic students was reported to be provided and administered by the disability units at public universities.

This study substantiated Taylor et al.'s (2016) study where they stated that that disability support within universities were provided in different forms, and to varying degrees, in that the needs of dyslexic students at public universities exist on a spectrum. Some participants in this research indicated that most of their needs were met by the university while others indicated that only some of their needs were met. One example was the issue of lack of access to lecture notes and/or slides after class, which was a recurring complaint of the participants in this study. Therefore, findings from this study show that the attitudes of lecturers and tutors' range on a spectrum from being dismissive (negative) towards dyslexic students, to being supportive (positive). Nolan et al. (2014) noted that negative lecturer attitudes are sometimes due to a sense of helplessness rather than an indifference on the part of academic staff. The needs of dyslexic students differ from individual to individual even though all dyslexic students experience the same or similar characteristics of dyslexia. However, those participants who disclosed their status to their university reported that their needs were generally met. Nevertheless, all participants reported that more could be done by university staff to ensure a better student experience.

\section{RECOMMENDATIONS AND CONCLUSION}

The findings and conclusions of this study highlight the need for universities to be aware of the experiences of the dyslexic student at public universities. This awareness is imperative to understand these students' challenges and therefore accommodate their needs so that they may have the same opportunity at academic success as their non-dyslexic peers. Recommendations are provided in the form of practical guidelines for universities so that the experiences and academic success of dyslexic students may be improved: 


\section{Practical guidelines}

\section{- Guideline 1: Advertising support resources and services}

Universities should advertise their student support services on a continuous basis so that dyslexic students are aware of concessions and accommodations from their first year of study.

\section{- Guideline 2: Accommodation of different learning styles}

Universities should adapt their teaching and learning design to allow the dyslexic student an equal opportunity for academic success as their peers. For example, a blended approach to teaching and learning allows the dyslexic student flexibility to learn at their own pace and revisit difficult concepts in various forms, i.e., traditional lectures as well as online platforms.

\section{- Guideline 3: Access to lecture resources}

Universities should make lecturer notes, slides and other resources available to students before or after the lecture. This allows the dyslexic student to access the resources in their own time and at their own pace in order to consolidate difficult concepts.

The findings offer valuable insights into the lived experiences of dyslexic students at public universities in South Africa. This study reveals that dyslexic students encounter various challenges in their experience of university life, but that they use several techniques they have in their arsenal to overcome these challenges.

The disclosure of one's dyslexic status at university is advantageous as it offers the student the opportunity to access the necessary concessions and accommodations. Utilising the formal support offered by the university is beneficial to the dyslexic student as it can reduce anxiety levels during assessment and examination settings. However, the daily anxiety levels associated with the effects of the characteristics of dyslexia are still very high for dyslexic students. This anxiety has a negative impact on their experiences of university. The main barrier to learning that emerged from this study is the lack of societal awareness about dyslexia and the significant negative impact this has on the experience of dyslexic students at university. A conclusion that can be drawn from this study is that lecturers and tutors are generally lacking in their knowledge and understanding of the impact of dyslexia on students. This lack of knowledge can have a detrimental effect on students' experiences and, ultimately, on their academic success. Yet 
despite the barriers that dyslexic students face at university, they employ many self-taught coping mechanisms to overcome daily obstacles. Many of them attribute their academic success to their coping mechanisms, irrespective of the challenges they face. It can then be argued that dyslexic students rely on their own ability to fit into society rather than on society accommodating their needs. Nevertheless, dyslexic students value the support they receive from their respective universities.

In conclusion, despite the daily academic challenges and lack of societal awareness that dyslexic university students experience, they continue to achieve academic success.

\section{REFERENCES}

Beckett, Jonathan, P. and Judith A. Darnell. 2020. "“A' for Attitude - Attitudes towards Dyslexia in Higher Education." Global Research in Higher Education 3(2): 52-58. doi:10.22158/ grhe.v3n2p52.

Cameron, Harriet and Karl Nunkoosing. 2012. "Lecturer perspectives on dyslexia and dyslexic students within one faculty at one university in England." Teaching in Higher Education 17(3): 341-352. doi:10.1080/13562517.2011.641002.

Carroll, J. M. and J. E. Iles. 2006. "An assessment of anxiety levels in dyslexic students in higher education." British Journal of Educational Psychology 73(3): 651-652. doi:10.1348/ $000709905 X 66233$.

Denhart, Hazel. 2008. "Perceptions of Students Labelled with Learning Disabilities in Higher Education.” Journal of Learning Disabilities 41(6): 483-497. doi:10.1177/0022219408321151.

Doering, Jonathan. 2003. “An Unusual Balance of Skills: Dyslexia in Higher Education.” Contemporary Review 282(1645): 99-104. http://0-eds.b.ebscohost.com.oasis.unisa.ac.za/eds/pdfviewer/ pdfviewer?sid=7f489f51-84ae-467c-bec7-5987e3818115\%40sessionmgr101\&vid=4\&hid=114.

Doikou-Avlidou, Maro. 2015. "The Educational, Social and Emotional Experiences of Students with Dyslexia: The Perspective of Postsecondary Education Students." International Journal of Special Education 30(1): 132-145. http://files.eric.ed.gov/fulltext/EJ1094794.pdf.

FOTIM see Foundation of Tertiary Institutions of the Northern Metropolis

Foundation of Tertiary Institutions of the Northern Metropolis. 2011. "Disability in Higher Education." https://www.uct.ac.za/usr/disability/reports/annual report 10 11.pdf.

Henderson, Paul. 2017. "Are there delays in reporting dyslexia in university learners? Experiences of university learning support staff." Journal of Further and Higher Education 41(1): 30-43. doi:10.1080/0309877X.2015.1023563.

Heiman, Tai and Karen Precel. 2003. "Students with Learning Disabilities in Higher Education: Academic Strategies Profile." Journal of Learning Disabilities 36(3): 248-258. http://duke.edu/arc/documents/Heiman\%20Learning\%20Disabilities.pdf.

IDA see International Dyslexia Association.

International Dyslexia Association. 2008. "Dyslexia Basics." www.interdys.org/FactSheets.htm.2004. "Social and Emotional Problems related to Dyslexia." Just the Facts. Baltimore, MD: IDA.

Lapraik, Susan Jane. 2012. Dyslexic Students Preparing for Examinations in Higher Education: Strategies and a Sense of Control. University of Southampton.

Lightfoot, Amy, Roya Janemi, and Debbie Laliberte Rudman. 2018. "Perspectives of North American Postsecondary Students with Learning Disabilities: A Scoping Review." Journal of Postsecondary Education and Disability 31(1): 57-74. 
Lopez-Escribano, Carmen, Judith Suro Sanchez, and Fernando Leal Carretero. 2018. "Prevalence of Developmental Dyslexia in Spanish University Students." Brain Sciences 8(82): 1-15. doi:10.3390/brainsci8050082.

Lyner-Cleophas, Marcia, Estelle Swart, Tsitsi Chataika, and Diane Bell. 2014. "Increasing access into higher education: Insights from the 2011 African Network on Evidence-to-Action on Disability Symposium - Education Commision." African Journal of Disability 3(2): 1-3. doi:10.4102/ajod.v3/2.78.

MacCullagh, Lois. 2014. "Participation and experiences of students with dyslexia in higher education: a literature review with an Australian focus." Australian Journal of Learning Difficulties 19(2): 93-111. doi:10.1080/19404158.2014.921630.

MacDonald, Stephen J. 2010. "Towards a social reality of dyslexia." British Journal of Learning Disabilities 38 (4): 271-279. doi:10.1111/j.1468-3156.2009.00601.x.

MacDonald, Stephen J. 2009. "Windows of Reflection: Conceptualizing Dyslexia Using the Social Model of Disability." Dyslexia 15: 347-362. doi:10.1002/dys.

Maggiolini, Silvia and Paola Molteni. 2013. "University and Disability: An Italian Experience of Inclusion." Journal of Postsecondary Education and Disability 26(3): 249-262. https://files.eric.ed.gov/fulltext/EJ1026887.pdf.

Matshedisho, Knowledge Rajohane. 2010. "Experiences of disabled students in South Africa: Extending the thinking behind disability support." South African Journal of Higher Education 24(5): 730744.

Morrison, John, Handre Brand, and Charl Cilliers. 2009. "Students with Disabilities in Higher Education." Acta Academica 41(3): 201-223. htpp://www.ufs.ac.za/ActaAcademia>.

Mortimore, Tilly and W. Ray Crozier. 2006. "Dyslexia and difficulties with study skills in higher education." Studies in Higher Education 31(2): 235-251. doi:10.1080/03075070600572173.

Mullins, Lara and Michele Preyde. 2013. "The lived experience of students with an invisible disability at a Canadian university." Disability and Society 28(2): 147-160. doi:10.1080/09687599.2012.752127.

Mutanga, Oliver. 2018. "Inclusion of Students with Disabilities in South African Higher Education." International Journal of Disability, Development and Education 65(2): 229-242. doi:10.1080/1034912X.2017.1368460.

Nolan, Clodagh, Claire Gleeson, Declan Treanor, and Susan Madigan. 2014. "Higher education students registered with disability services and practice educators: issues and concerns for professional placements." International Journal of Inclusive Education, 1-16. doi:10.1080/13603116. 2014.943306.

Ntombela, Sithabile. 2013. "Inclusive education and training in South African higher education: Mapping the experiences of a student with physical disability at university." Africa Education Review 10 (3): 483-501. doi: 10.1080/18146627.2013.853541.

Pino, Marco and Luigina Mortari. 2014. "The Inclusion of Students with Dyslexia in Higher Education: A Systematic Review Using Narrative Synthesis.” Dyslexia 20: 346-369. doi:10.1002/dys.1484.

Pirttimaa, Raija, Marjatta Takala, and Tarja Ladonlahti. 2015. "Students in higher education with reading and writing difficulties." Education Inquiry 6(1): 5-23. doi:10.3402/edui.v6.24277.

Riddick, Barbara. 2001. "Dyslexia and Inclusion: time for a social model of disability perspective?" International Studies in Sociology of Education 11(3): 223-236. doi:10.1080/ 09620210100200078.

Ryan, Janette and John Struhs. 2004. "University education for all? Barriers to full inclusion of students with disabilities in Australian universities." International Journal of Inclusive Education 8(1): 7390. doi:10.1080/1360311032000139421.

Shevlin, M., M. Kenny, and E. Mcneela. 2004. "Participation in higher education for students with disabilities: An Irish perspective." Disability \& Society 19(1): 15-30. doi:10.1080/ 0968759032000155604. 
Taylor, Mark, Yvonne Turnbull, Jo Bleasdale, Hulya Francis, and Henry Forsyth. 2016. "Transforming support for students with disabilities in UK Higher Education.” Support for Learning 31(4): 367384. doi:10.1111/1467-9604.12143.

Toutain, Christopher. 2019. "Barriers to Accommodations for Students with Disabilities in Higher Education: A Literature Review." Journal of Postsecondary Education and Disability 32(3): 297310.

Vickerman, Phillip and Milly Blundell. 2010. "Hearing the voices of disabled students in higher education." Disability and Society 25(1): 21-32. doi:10.1080/09687590903363290. 